\title{
Online Teaching in the Age of Covid-19: A Case Study at the Merchant Marine Academy's Engineering School of Macedonia, Seated in Nea Michaniona
}

\author{
Mary Matsouka, Areti Valasidou, and Vasileios Dagdilelis
}

\begin{abstract}
The coronavirus pandemic has affected educational systems around the world, leading most universities to implement distance education. The aim of this research is to investigate the application of online education at the School of Engineering in Nea Michaniona, Thessaloniki during the covid19 pandemic, according to the views of its educators. The survey was conducted at the end of the spring semester of 2020 . A combination of quantitative and qualitative methods was used with the tool of a questionnaire with closed and open-ended questions to 32 educators. The findings of the study revealed the problems faced by educators, the modifications they had to make, their view on the quality of the teaching they provided, the limitations of a technical school and their future intentions regarding distance learning.
\end{abstract}

Keywords - Covid-19, distance education, engineering education, online teaching.

\section{INTRODUCTION}

At the Merchant Marine Academies (MMA) in Greece, the training of Engineers and Captains of the Merchant Navy takes place, with the Sandwich courses system. The studies include six semesters of theoretical training at the school with lectures and laboratory courses and two semesters of maritime practical training on a merchant ship. MMA, in order to comply with the preventive measures to limit the spread of the new coronavirus covid-19, suspended its operation on March 11, 2020, for the entire spring semester and replaced all educational activities with similar online ones. In other words, it was unavoidable to move from a model of enriching lifelong learning with Information and Communication Technologies to a model of integrated elearning [1].

The period of the pandemic was a new experience for everyone, with the International Association of Universities emphasizing that the transition from face-to-face to distance learning did not occur without challenges, such as access to technical infrastructure, educational adequacy in distance teaching, as well as the requirements that some specific areas of education may have. Research has shown a cautious attitude of both educators and students towards the forced transition from face-to-face education to distance teaching and learning. At the same time, however, it is a great opportunity for educational institutions to proceed with the

Submitted on November 4, 2021.

Published on February 16, 2022.

Mary Matsouka, Department of Educational \& Social Policy, University of Macedonia, Greece.

(e-mail: matsouka@uom.edu.gr) digital transformation of the education they provide [2]-[5]. This situation has raised intense research interest in identifying the factors that influence distance learning activities.

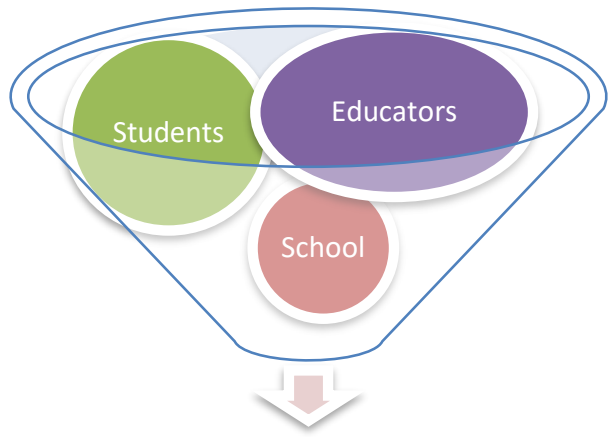

Fig. 1. Online education success

\section{LITERATURE REVIEW}

The quality of distance learning provided in response to an emergency varies greatly, depending on the available technical infrastructure, the ability of teaching staff to adapt to e-learning and the field of study [4]. More specifically, Webster \& Hackley concluded that the overall success of online education depends on the experience and attitude of educators and learners towards technology [6].

However, according to Ali, the implementation of online education is not just a technical issue and should be seen as a pedagogical and educational challenge [2]. Moore in the theory of Interactive Distance argues that learning is related to the communication and psychological distance of those involved in the educational process and the educator should provide support to the learner not only with educational material, but mainly through communication with each other [7]. Bao argues that it is necessary to take specific actions to improve the degree and depth of student participation in the classroom and thus the role of educators is very important [8].

The same researcher emphasizes that the technical requirements of online teaching are much more important than those in traditional teaching and there must be support from the educational institution. When the institution has supportive policies, such as access to new technologies and digital guidance, as well as more crucial ones such as

Areti Valasidou, Hellenic Open University, Greece.

(e-mail: valasidou.areti@ac.eap.gr)

Vasileios Dagdilellis, Department of Educational \& Social Policy, University of Macedonia, Greece.

(e-mail: dagdil@uom.edu.gr). 
reducing teaching time, flexibility, and encouragement to use innovative teaching methods, then educators are motivated to teach lessons via the internet [9].

De Gagne \& Walters revealed that educators need to be trained how to teach online, while the school should provide them with resources and support because online teaching requires more time and effort than face-to-face teaching [10].

Finally, another important challenge mentioned in relation to teaching and distance learning is the limitations that exist due to the nature of the curriculum in some specialties that require direct access to practical exercises. In medical Schools, polytechnics and art Schools, laboratory courses are a challenge and the teaching provided during the pandemic is often limited to the theoretical dimension of the curriculum [4].

In the context of all the previous findings of the literature review, it was considered useful to conduct a research among the educators of MMA Macedonia in order to capture their relevant views and to investigate the advantages and limitations that arise with the online teaching during the period in which all school operations were suspended due to coronavirus.

Furthermore, the research conducted aimed to give answers to the following research questions:

1. What are the most important problems, difficulties and limitations faced by MMA educators during distance learning?

2. What did the MMA educators have to differentiate in their teaching during teaching in distance education?

3. What do the MMA educators think about the quality of the course in distance education in relation to the course with physical presence?

4. Are there differences in distance learning of theoretical and laboratory courses?

5. Which form of education is more difficult to apply to studies at MMA according to educators?

6. What form of education do MMA educators prefer in the post-covid era?

\section{RESEARCH METHODOLOGY}

The present research was carried out at the Merchant Marine Academy of Macedonia, in the spring semester of 2020. Thirty two educators of the School of Engineering, of different specialties, participated, who provided distance learning, in their regular program.

The tool that was used to conduct the research was the questionnaire, which included closed-ended questions for recording quantitative information, as well as open-ended questions aimed at a qualitative approach to the phenomenon [11].

In its final form, the questionnaire included 24 statements organized in four groups: general information (semester and type of course), technological issues (equipment and internet connection), survey of teachers' views on some key issues (communication, adaptation, preferences) and problems that arise (technical issues, inability to do laboratory exercises, lack of interaction). The questions were closed-ended and used a Likert scale with 5 answer options $(1=$ at all, $2=$ a bit, $3=$ enough, $4=$ much, $5=$ very much). In the questionnaire, there were also open-ended questions, including one that examined educators' views on the quality of teaching during online education.

The questionnaire was initially distributed to a team of experts (two distance education scientists and a computer science professor at MMA Michaniona) who confirmed its validity, examining its completeness, clarity, coherence and structure. It was then given for pre-test to 3 educators (who were excluded from the research sample) to measure the degree of understanding, acceptance and correct interpretation of the questionnaire [12].

The reliability of the questionnaire was then examined using the Cronbach alpha coefficient value used to assess internal consistency reliability. The questionnaire was considered reliable as the Cronbach's reliability coefficient $\mathrm{a}=0.88$, which shows good reliability [13].

The results of the research must be evaluated cautiously, since it was conducted on a small number of educators which was a convenience sample, so it is not representative of the general educators' population so that we can draw general conclusions. In order to develop a holistic view and to capture educators' views more safely, it is necessary to follow largerscale research on a random sample.

The data were collected using an online questionnaire in the Google Forms application and distributed to all educators, through the Microsoft Teams platform, from 11/6 to 23/6 of 2020 during the spring semester. This was done after the purpose was explained by the researchers of the investigation and after the anonymity and confidential use of the data had been confirmed. Thus, a high degree of cooperation was achieved between the researchers and the respondents in order to arrive to complete and consistent results in the shortest possible time.

Both qualitative and quantitative data were used for the analysis. The software package SPSS 24.0 was used for the analysis of the data from the questionnaires. The results were recorded by checking the research hypotheses that emerged from the research goals, with the ultimate goal of drawing conclusions and verifying or not the research hypotheses. Thus, the process of assumption testing with the help of $\mathrm{x}^{2}$ (chi-square test) is presented. Finally, the level of statistical significance ( $p$-value) for the needs of research data processing was set at 0.05 .

\section{RESULTS ANALYSIS}

At this section there will be a presentation of the results of the hypothesis testing of the quantitative research.

1) Educators of theoretical majors adapted more easily e-learning than educators of laboratory majors

First, inferential statistics should be used and then hypothesis testing [11]. The two questions that will be considered are the type of courses taught by the respondents and the ease of adaptation to the new way of teaching the courses. The easiest adjustment can be interpreted by the options for "much" and "very much" answers.

The majority of educators of theoretical majors answered that "easily" (58.3\%) and "very" easily (16.7\%) adapted to elearning. On the contrary, about $31 \%$ gave the answers "very" and about $31 \%$ "very much" from the educators who teach 
laboratory courses. So, it seems that in total (at a rate of 75\%) the educators of the theoretical courses adapted to the distance learning as easily as the teachers of the laboratory courses (at a rate of $71 \%$ ). Therefore, the null hypothesis is verified, and it is finally found that both theoretical and laboratory educators found it easy to adapt to e-learning.

2) In laboratory classes, more time is needed during teaching

First, inferential statistics should be used and then hypothesis testing [11]. The two questions that will be considered are the type of courses taught by the respondents and whether distance learning makes the course more time consuming than if the course is taught face to face in a physical classroom. The second question concerns the answers "much" and "too much".

The majority of theoretical educators answered that "not very" easily $(66.7 \%)$ and "a bit" $(8.3 \%)$ agree with the view that the lesson in distance education is more time consuming. On the other hand, about $38.5 \%$ gave the answers "much" and about $23.1 \%$ "very much" from the teachers who teach laboratory courses. So, it seems that in total $(61 \%)$ the educators of the laboratory courses consider that with distance education the course becomes more time consuming while only 16.7 of the teachers of the theoretical courses agree with the view that their course becomes time consuming with distance learning. Therefore, the alternative hypothesis is verified, and it is found that laboratory teachers consider that more time is needed to teach a laboratory course in distance education. The same result was reached by Müller et al, who pointed out the increased time and effort required for distance learning [14].

3) Distance learning is more tiring than lifelong learning

Initially, descriptive statistics should be used and the question to which it will be applied with the help of percentages is the $3^{\text {rd }}$ question from the $3^{\text {rd }}$ Section of the questionnaire and concerns the respondents' point of view in the statement "Distance teaching makes me more tired than face to face teaching".

TABLE I: DISTANCE LEARNING IS MORE TIRING THAN LIFELONG LEARNING

\begin{tabular}{cccccc}
\hline & Frequency & Percent & $\begin{array}{c}\text { Valid } \\
\text { Percent }\end{array}$ & $\begin{array}{c}\text { Cumulative } \\
\text { Percent }\end{array}$ \\
\hline Valid & 1 & 7 & 21,9 & 21,9 & 21,9 \\
& 2 & 2 & 6,3 & 6,3 & 28,1 \\
3 & 5 & 15,6 & 15,6 & 43,8 \\
4 & 10 & 31,3 & 31,3 & 75,0 \\
5 & 8 & 25,0 & 25,0 & 100,0 \\
Total & 32 & 100,0 & 100,0 & \\
\hline
\end{tabular}

Over $56 \%$ of respondents generally agree that it is more tiring to teach via distance than in a traditional class. Of course, it is worth mentioning at this point that a significant percentage (about 22\%) of respondents answered that they strongly agree with this view. So, the research hypothesis is being verified and therefore most teachers find e-learning tedious, which is also evident from the fact that in their comments they mention exhaustion as one of the most important problems they have had to face.

\section{4) MMA educators prefer distance education in the post} COVID-19 era

Initially descriptive statistics should be used and the question to which it will be applied with the help of percentages is the $12^{\text {th }}$ question from the $3^{\text {rd }}$ Section of the questionnaire and concerns the expression of the respondents' point of view in the statement "I would like to introduce this way of teaching in our school".

About $72 \%$ of the respondents give the answer that the desire to establish e-learning as a way of teaching in MMA doesn't apply to them. A small percentage (about 12.5\%) of the respondents answered that they "strongly" agree with this view. Therefore, the research hypothesis is not verified and therefore most of the MMA educators do not prefer distance education in the post-covid era.

TABLE II: MMA EdUCATORS PREFER Distance EdUCATION IN THE Post

\begin{tabular}{lccccc}
\multicolumn{5}{c}{ COVID-19 ERA } \\
\hline Valid & Frequency & Percent & $\begin{array}{c}\text { Valid } \\
\text { Percent }\end{array}$ & $\begin{array}{c}\text { Cumulative } \\
\text { Percent }\end{array}$ \\
\hline & 1 & 23 & 71,9 & 71,9 & 71,9 \\
& 2 & 2 & 6,3 & 6,3 & 78,1 \\
& 3 & 1 & 3,1 & 3,1 & 81,3 \\
& 4 & 4 & 12,5 & 12,5 & 93,8 \\
& 5 & 2 & 6,3 & 6,3 & 100,0 \\
\multicolumn{2}{c}{ Total } & 32 & 100,0 & 100,0 & \\
\hline
\end{tabular}

Furthermore, the results of the research questions of the qualitative research are presented. According to the comments of the educators collected by the questionnaires, there are some representative answers per research question presented in order to highlight their experience in distance learning.

Regarding the first research question, although the teachers have the required degree of familiarity with technology, K31 states: "There are serious technical problems due to low speed in the home network of teachers and students" and K16: "I get very tired in front of a screen for many hours, it is not pleasant". In addition, an important factor for the success of distance education is the teacher-student interaction, which allows teachers to see the effectiveness of their teaching [15]. More specifically, K6: "The student loses contact with the teacher as well as the teacher's perception of whether what he taught was understood" and K30: "What bothers me is that students cannot stay focused. There are various things that may distract them".

Regarding the $2^{\text {nd }}$ research question, several teachers referred to the fact that their role has changed. K11 states that: "I had to differentiate my teaching techniques to make the lesson more attractive" and K2: "The material should be reduced. Half an hour of the lesson was lost because we had to solve problems with the internet connection".

There was intense concern in the educational community about the quality of the courses in distance education. Answering the $3^{\text {rd }}$ and $4^{\text {th }}$ research questions, we notice that most of them place special emphasis on the type of courses they taught. K1 states: "Concerning the courses that I teach, which are in laboratory, the quality of education has fallen". While respectively K32: "In theoretical courses the quality of education does not differentiate. The lessons that are taught online are characterized by greater participation of those who are really interested in learning". According to UNESCO, in the field of technical education, the theoretical part of the 
courses can be taught online in order to improve access to a better quality in education [16]. However, in the field of engineering and science there is a need for innovative approaches to limit the lack of practical experience.

Finally, in the last two research questions, referring to the problems and difficulties faced by the teachers, and also the fact that it is an Academy with many laboratory courses and mandatory internships, almost all teachers were negative about implementing distance education at MMA. However, it should be noted that teachers in purely theoretical subjects seem to be more positive in distance learning, but even them realize the difficulties that arise when laboratory exercises have to be demonstrated. The majority of teachers, as shown by the quantitative research, agree that online education is more difficult to apply in MMA.

\section{DISCUSSION}

With the spread of the coronavirus, the global educational community has faced a major challenge, with educators having to adapt the online teaching, in most cases without prior training or experience. The research findings revealed three categories of problems faced by MMA educators during online teaching including technological limitations, exhaustion, and lack of effective communication with students. The results can be combined with those of relevant research, which have been presented in the literature review part of the paper.

Distance learning should not be limited to the sharing of educational material and information but should provide communication and interaction between teachers and students. We reached the same conclusion in the corresponding research with the students of MMA, who argued that one of the most important factors affecting their participation in the course is the degree and quality of their interaction and communication with their teachers [17]. In order to achieve better communication, teaching should be designed and organized in a way that involves students in the educational process [4]. The educators noticed that in order to enhance the interest and commitment of students, they needed to change their teaching material, teaching methods and make full use of the available online tools.

However, one of the factors that determine the effectiveness of online teaching is the quality of teaching, compared to the face-to-face course. Thus, a strong variation was identified depending on the type of courses taught by the teachers. Regarding the theoretical courses, the analysis of data shows that a safe answer cannot be given. More than half of the teachers said that the quality of the lesson might be better because all the digital teaching tools are available and the lectures are attended only by those who are really interested, as a result of which the teaching process becomes easier and more interesting. On the other hand, teachers of the laboratory courses are unconditional. The quality of laboratory exercises using simulation cannot be compared with that of workshops inside the classroom, where students have the opportunity to practice and interact effectively with their classmates and teachers.

Moreover, based on the results of the research, it can be argued that distance education is a necessary solution in the period of the coronavirus pandemic, but it requires special arrangements and changes. The majority of MMA educators stated that distance learning is more tiring and timeconsuming process than if the course is taught face-to-face in a physical class and that it is very difficult to apply it in the MMA School of Engineering, where laboratories play an important part of the curriculum. Also, to a very large extent, there are setbacks in the perspective of integration of elearning in the educational process, when schools start to operate with face-to-face lessons.

\section{REFERENCES}

[1] Sofos A., Kostas A. and Paraschou B. Online Distance Education Athens: Hellenic Academic Libraries Link, 2015, ch, 1, pp. 23-28. Retrieved from http://hdl.handle.net/11419/182.

[2] Ali W. Online and Remote Learning in Higher Education Institutes: A Necessity in light of COVID-19 Pandemic. Higher Education Studies, May 2020:10(3). https://doi.org/10.5539/hes.v10n3p16.

[3] Doukakis S. and Alexopoulos E.C. The Role of Educational Neuroscience in Distance Learning. Knowledge Transformation Opportunities. Visions and Concepts for Education 4.0. ICBL 2020, ed. Auer M.E. and Centea D., Advances in Intelligent Systems and Computing, vol 1314. Springer, Cham, 2021 https://doi.org/10.1007/978-3-030-67209-6_18.

[4] Marinoni G., Land H. and Jensen T. The impact of Covid-19 on higher education around the world. IAU Global Survey Report. May 2020. [Online]. Available: https://www.iauaiu.net/IMG/pdf/iau_covid19_and_he_survey_report_final_may_202 $0 . p d f$.

[5] Nikiforos S., Tzanavaris S. and Kermanidis K.L. Post-pandemic Pedagogy: Distance Education in Greece During COVID-19 Pandemic Through the Eyes of the Teachers. European Journal of Engineering and Technology Research, CIE, December 2020. https://doi.org/10.24018/ejers.2020.0.CIE.2305.

[6] Webster J. and Hackley P. Teaching Effectiveness in TechnologyMediated Distance Learning. Academy of Management Journal, December 1997;40(6):1282-1309. Retrieved from https://www.jstor.org/stable/257034.

[7] Moore M. G. Theory of transactional distance. New York: Routledge: Theoretical Principles of Distance Education, ed. D. Keeg, pp. 22-38, 1993.

[8] Bao W. COVID 19 and online teaching in higher education: A case study of Peking University. Human Behavior and Emerging Technologies, April 2020;2(2):113-115. https://doi.org/10.1002/hbe2.191.

[9] Chapman D. D. Contingent and Tenured/Tenure-Track Faculty: Motivations and Incentives to Teach Distance Education Courses. Online Journal of Distance Learning Administration, vol. 14, no 3, pp. 1-16, Fall 2011. Retrieved from https://www.westga.edu/ distance/ojdla/fall143/chapman143.html.

[10] De Gagne J. C. and Walters K. J. The Lived Experience of Online Educators: Hermeneutic Phenomenology. MERLOT Journal of Online Learning and Teaching, June 2010;6(2). Retrieved from http://jolt.merlot.org/vol6no2/degagne0610.htm.

[11] Zafeiropoulos K. How is a scientific work done? Scientific reseasch and writting assignments, 2nd ed. Athens: Kritiki, 2015, ch. 5, pp. 9195 and ch. 8, pp. 192-229.

[12] Bell J. Methodological Design of pedagogical and social research: Guide for stydents and PhD students, 2nd ed. Athens: Gutenberg, 2001, ch. 7, pp. 134-141.

[13] Galanis P. Validity and reliability of questionnaires in epidemiological studies. Archives of Hellenic Medicine, January 2013;30(1):97-110. Retrieved from http://www.mednet.gr/archives/2013-1/pdf/97.pdf.

[14] Müller A. M., Goh C., Lim L. and Gao S. Covid-19 emergency elearning and beyond: Experiences and perspectives of university educators. Education Sciences, January 2021;11(1):1-15. https://doi.org/10.3390/educsci11010019.

[15] Sharma R. D. and Jyoti J. Job satisfaction of university teachers: An empirical study. Journal of Services Research, 2009;9(2):51-80. Retrieved from https://www.semanticscholar.org/paper/JOBSATISFACTION-OF-UNIVERSITY-TEACHERS\%3A-ANSTUDY-SharmaJyoti/60558ded7ef19eeb6f6153eba8a8ca7107e96eb8. 
[16] Matsouka M., Valasidou A. and Dagdilelis V. Online learning in the era of Covid-19: A case study of the Merchant Marine Academy's Engineering School. Open Education: The Journal for Open and Distance Education and Educational Technology, April 2021;17(1): 150-167. Retrieved from:

[17] https://ejournals.epublishing.ekt.gr/index.php/openjournal/article/view $/ 25429$ https://doi.org/10.12681/jode.25429.

[18] UNESCO Education Sector. (June 2020). Quality assurance and recognition of distance higher education and TVET. UNESCO COVID19 education response: education sector issue notes, no. 5.1. Retrieved from https://unesdoc.unesco.org/ark:/48223/pf0000373754.

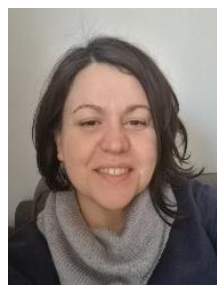

Mary Matsouka obtained a diploma (M.Eng.) in Mechanical Engineering ( 5 years) from the Aristotle University of Thessaloniki, Greece, a Master of Sciences Degree from the Hellenic Open in Engineering Project Management and she is a $\mathrm{PhD}$ student in the University of Macedonia, Thessaloniki, Greece.

She is a Lecturer at Merchant Marine Academy of Macedonia, Greece and she has been a part-time Lecturer at Technological Education Institutes since 2002. Her research interests are mainly focused on the Teaching of Engineering. Mrs. Mary Matsouka has participated in many Greek and international Conferences. She is a member of the Greek Technical Chamber.

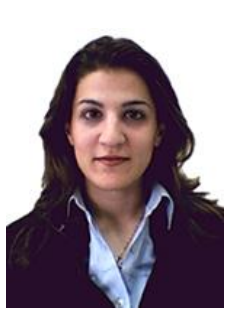

Dr. Areti Valasidou was born in Drama, Greece. She obtained Bachelor of Science in Applied Informatics, University of Macedonia, Thessaloniki, Greece (2000), Master of Science in Business Information Technology Systems, Strathclyde University, Glasgow, UK (2001), Master of Arts in Sciences of Education, Cyprus Open University (2011) and PhD in Distance Education and Technologies, University of Macedonia, Thessaloniki, Greece (2005). She is parttime Lecturer in New Technologies and Distance Education at the Hellenic Open University, Greece. She teaches management information systems, basics of computers and teaching techniques for computers. Her academic interests are in the field of distance education with new technologies, e-learning and management information systems.

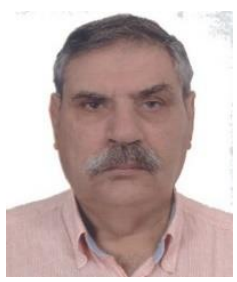

Vasileios Dagdilelis obtained a diploma (B.Sc) in Mathematics (4 years) from the Aristotle University of Thessaloniki, Greece, a Master's Degree from the University of Grenoble, France and a $\mathrm{PhD}$ in Didactics of Informatics from the University of Macedonia, Thessaloniki, Greece.

$\mathrm{He}$ is a retired Professor of the University of Macedonia. His research interests are mainly focused on the Didactics of Mathematics and Informatics.

Dr Vasileios Dagdilelis has numerous publications in scientific journals and participated in many Greek and international Conferences. He is a member of Greek and international scientific associations. 